\title{
Pengembangan Granul Herbal Kumis Kucing, Temulawak, dan Pegagan dengan Pengisi Maltodextrine dan Spray Dried Lactose
}

\author{
Roisah Nawatila, Aditya Trias Pradana, Diva Amadea Nabilla, Fransiska Levina Oktaviani, \\ Rista Noer Efendi, Ade Ayu Kintan Anjarsari, Chintya Dewi Tanuwijaya, dan Rahma Anida \\ Putri
}

Departemen Farmasetika, Fakultas Farmasi, Universitas Surabaya, Surabaya, Indonesia

Korespondensi: Aditya Trias Pradana

Email: aditya_trias@staff.ubaya.ac.id

Submitted : 02-03-2020, Revised : 12-04-2020, Accepted : 31-05-2020

\begin{abstract}
ABSTRAK : Jamu masih sangat diminati oleh penduduk Indonesia. Tingginya angka penggunaan jamu dan didukung dengan angka keberhasilan manfaat jamu, menjadikan jamu lebih banyak dikembangkan. Pada tahun 2013 terdapat dua formula jamu saintifik, yaitu jamu untuk hiperurisemia dan hipertensi. Daun kumis kucing (Orthosiphon stamineus), rimpang temulawak (Curcuma xanthorrhiza), dan herba pegagan (Centella asiatica) memiliki khasiat dalam mengatasi hipertensi ringan, namun masih memiliki rasa yang kurang enak. Oleh karena itu, pada penelitian ini dilakukan pengembangan produk herbal yang inovatif berupa granul yang dibuat dengan metode granulasi kering dengan pengisi maltodextrine dan spray dried lactose (SDL). Pada formula 1 menggunakan maltodextrine, formula 2 menggunakan SDL, dan formula 3 menggunakan kombinasi dari kedua pengisi $(1: 1 \mathrm{~b} / \mathrm{b})$. Tujuan penelitian ini adalah untuk menentukan pengaruh jenis pengisi terhadap distribusi ukuran partikel, bobot jenis, sifat alir, waktu rekonstitusi, dan pH granul herbal. Data mutu fisik dianalisis statistik menggunakan metode oneway ANOVA $(\alpha=0,05)$. Hasil penelitian menunjukkan bahwa pengisi maltodextrine memberikan mutu fisik (terutama pada sifat alir) yang lebih optimal apabila dibandingkan dengan menggunakan pengisi spray dried lactose atau kombinasi keduanya.
\end{abstract}

Kata kunci: kumis kucing; temulawak; pegagan; maltodextrine; spray dried lactose; granulasi kering

ABSTRACT: Jamu is still popular and has great demand by the population of Indonesia. The highly used and success rate of herbal medicine in giving benefits, has made herbal medicine development increasing. In 2013 there were two scientific jamu formulas, i.e. for hyperuricemia and hypertension. Orthosiphon stamineus leaves, Curcuma xanthorrhiza rhizome, and Centella asiatica herb were used and have properties to treat mild hypertension, but their tastes are less acceptable. Therefore, innovative herbal products were developed in this study; in the form of granules that made by the dry granulation method with maltodextrine and spray dried lactose (SDL) as fillers. Maltodextrine, $S D L$, and their combination (1:1 w/w) were used in formula 1, 2 and 3, respectively. The purpose of this study was to determine the effect of filler types on the physical characteristics (particle size distribution, density, flowing properties, reconstitution time and $p H$ ) of herbal granules. Physical characteristic data were then analyzed statistically using the oneway ANOVA $(\alpha=0.05)$. The results showed that maltodextrine provide more optimal physical characteristics (especially in the flow characteristics of granules) when compared to SDL or combination of maltodextrine and SDL.

Keywords: Orthosiphon stamineus; Curcuma xanthorrhiza; Centella asiatica; maltodextrine; spray dried lactose; dry granulation 


\section{Pendahuluan}

Jamu masih sangat diminati oleh penduduk Indonesia. Tingginya angka penggunaan jamu dan didukung dengan angka keberhasilan manfaat jamu, menjadikan jamu lebih banyak dikembangkan dengan dilakukannya penelitian terkait kemanan, khasiat, dan mutunya. Berdasarkan data Riset Kesehatan Dasar (Riskesdas) tahun 2010, menunjukkan bahwa sebanyak $60 \%$ penduduk Indonesia di atas usia 15 tahun menyatakan pernah minum jamu dan 90\% diantaranya menyatakan adanya manfaat dari minum jamu. Namun, pemanfaatannya selama ini masih sebatas pengobatan sendiri dan belum dilakukan di fasilitas kesehatan [1]. Pada tahun 2013 terdapat dua formula jamu saintifik, yaitu jamu untuk hiperurisemia dan hipertensi. Pada formula jamu saintifik untuk hipertensi ringan terdapat 3 komponen dasar, yaitu daun kumis kucing 3 gram, rimpang temulawak 3 gram, dan daun pegagan 3 gram [2]. Hipertensi adalah suatu kondisi pembuluh darah yang terus-menerus menerima tekanan, sehingga menjadi salah satu faktor resiko penyebab terjadinya coronary heart disease, stroke, dan aneurisma arteri. Penyakit ini merupakan penyebab kematian paling banyak di negara berkembang $[3,4]$. Akhir-akhir ini juga telah dilakukan beberapa penelitian terkait tanaman lokal yang memiliki efek antihipertensi [4].

Pada daun kumis kucing telah dilakukan penelitian sebelumnya bahwa kandungan methylripariochromene $A$ yang diisolasi dari daun kumis kucing tersebut dapat memberikan aktivitas antihipertensi. Sejumlah $100 \mathrm{mg} / \mathrm{kg}$ methylripariochromene $A$ dapat menurunkan tekanan darah sistolik saat disuntikkan secara subkutan pada tikus jantan [5]. Sedangkan, pada rimpang temulawak juga telah dilakukan penelitian sebelumnya bahwa xanthorrhizol dapat bertindak sebagai antagonis kalsium dengan mengurangi jumlah masuknya kalsium ke dalam pembuluh darah pada tikus jantan yang dapat menyebabkan vasodilatasi dan penurunan resistensi perifer pada pembuluh darah [6]. Selain itu, pada pegagan juga telah dilakukan penelitian sebelumnya bahwa hasil fraksinasi dari pegagan yang kaya akan triterpenoid ini memiliki efek antihipertensi setelah diujikan secara in vivo pada tikus jantan yang diinduksi fenilefrin [7]. Ketiga komponen tersebut memiliki khasiat dalam mengatasi hipertensi ringan, namun masih memiliki rasa yang kurang enak.

Berdasarkan fakta tersebut, maka dilakukan pengembangan produk herbal yang inovatif berupa produk nutrasetikal yang berbentuk granul untuk minuman herbal. Sediaan granul tersebut dibuat dengan metode granulasi kering. Metode granulasi kering merupakan metode yang sesuai untuk bahan aktif yang tidak tahan suhu tinggi dan memiliki daya alir yang buruk [8]. Prinsip dari metode ini adalah dengan mencampur seluruh partikel tanpa adanya cairan pengikat dan dikempa dengan mesin bertekanan tinggi hingga terbentuk aglomerat [9].

Bahan tambahan yang dapat digunakan pada granulasi kering memiliki kompresiblitas atau daya alir yang baik. Salah satu bahan tambahan yang dibutuhkan pada pembuatan granul adalah bahan pengisi (filler). Bahan pengisi merupakan zat inertyang ditambahkan pada campuran bahan aktif dalam jumlah tertentu untuk memperoleh massa campuran yang cukup pada saat dilakukan kompresi. Hal ini berfungsi untuk memperbaiki kecepatan alir dari massa granul [10]. Bahan pengisi yang digunakan dalam penelitian ini adalah maltodextrine dan spray dried lactose (SDL).

Maltodextrine merupakan bahan pengisi yang sering digunakan di industri farmasi, terutama sebagai pengisi tablet atau kapsul karena memiliki daya alir yang baik, tidak berwarna, tidak berbau, dan inert [11]. SDL memiliki karakteristik partikel yang tidak mudah rapuh, nilai LOD (loss on drying) 0,3-0,6\%, kompresibilitas yang baik, dan daya alir yang baik [12].

Pada penelitian ini, dibuat 3 macam formula dengan berbagai variasi pengisi, yaitu formula 1 (maltodextrine), formula 2 (spray dried lactose), dan formula 3 (kombinasi keduanya sebesar 1:1 b/b). Tujuan dari penelitian ini adalah untuk 
mengembangkan formula produk herbal jamu saintifik dengan mutu fisik yang baik meliputi distribusi ukuran partikel, bobot jenis, sifat alir, waktu rekonstitusi dan $\mathrm{pH}$, sehingga dapat meningkatkan efektifitas dan kenyamanan pasien dalam terapi hipertensi ringan.

\section{Metode}

\subsection{Bahan}

Simplisia kering herba kumis kucing (Orthosiphon stamineus) serta herba pegagan (Centella asiatica) didapatkan dari Balai Besar Penelitian dan Pengembangan Tanaman Obat dan Obat Tradisional (B2P2TOOT) Tawangmangu dan dideterminasi oleh Pusat Informasi dan Pengembangan Obat Tradisional Universitas Surabaya (masing-masing dengan sertifikat determinasi No. 1338/D.T/V/2018 dan 1337/D.T/V/2018). Simplisia kering rimpang temulawak (Curcuma xanthorriza) didapatkan dari Pasar Soponyono Kali Rungkut, Surabaya dan dideterminasi oleh Pusat Informasi dan Pengembangan Obat Tradisional Universitas Surabaya (sertifikat determinasi No. 1334/D.T/V/2018). Bahan kimia meliputi maltodextrine p.g (Cina), spray dried lactose p.g (Jerman),Sukrosafoodgrade(Indonesia), Natrium Siklamat p.g (Cina), HPMC p.g (Singapura), CMC$\mathrm{Na}$ p.g (Cina), PVP-K30 p.g (Cina), flavouring agent p.g (Singapura), Sodium Starch Glicolat p.g (India), dan Cab-O-Sil p.g (Jerman).

\subsection{Alat}

Alat penelitian meliputi neraca digital (Ohaus Scout Pro), mesin slugging (Erweka ${ }^{\circledR} \mathrm{GmbH}$, Germany), retsch vibrator (Test Sieve Retsch 5657 Haan W. Germany), moisture content tester (Ohaus MB45), tapping machine (Pharma Test D-63512, Germany), pH meter (Schott® Lab 850, Germany), dan alat-alat gelas laboratorium.

\subsection{Formula}

Formula sediaan granul herbal yang digunakan dalam penelitian ini dapat dilihat pada Tabel 1.

\subsection{Pembuatan serbuk simplisia}

Simplisia disortasi untuk memisahkan dari pengotor dan simplisia yang tidak bagus. Kemudian, hasil sortasi diserbuk dengan menggunakan blender. Selanjutnya, partikel serbuk diseragamkan ukurannya dengan

Tabel 1. Formula sediaan granul herbal

\begin{tabular}{llllllllllll}
\hline Bahan & Fungsi & \multicolumn{1}{l}{ F1 (\%) } & \multicolumn{3}{c}{ F2 (\%) } & \multicolumn{3}{c}{ F3 (\%) } \\
\cline { 2 - 11 } & & A & B & C & A & B & C & A & B & C \\
\hline Serbuk Kumis Kucing (1) & Bahan aktif & 20 & 20 & 20 & - & - & - & - & - & - \\
Serbuk Temulawak (2) & Bahan aktif & - & - & - & 20 & 20 & 20 & - & - & - \\
Serbuk Pegagan (3) & Bahan aktif & - & - & - & - & - & - & 20 & 20 & 20 \\
Maltodextrine & Pengisi & 44 & - & 22 & 46 & - & 23 & 46 & - & 23 \\
Spray Dried Lactose & Pengisi & - & 44 & 22 & - & 46 & 23 & - & 46 & 23 \\
Sukrosa & Pemanis & 15 & 15 & 15 & 15 & 15 & 15 & 15 & 15 & 15 \\
Sodium Siklamat & Pemanis & 4 & 4 & 4 & 4 & 4 & 4 & 4 & 4 & 4 \\
HPMC & Pengental & 1 & 1 & 1 & 1 & 1 & 1 & 1 & 1 & 1 \\
CMC-Na & Pengental & 2 & 2 & 2 & 2 & 2 & 2 & 2 & 2 & 2 \\
PVP-K30 & Pengikat & 5 & 5 & 5 & 5 & 5 & 5 & 5 & 5 & 5 \\
Perasa & Flavouring agent & 4 & 4 & 4 & 2 & 2 & 2 & 2 & 2 & 2 \\
Sodium Starch Glicolat & Disintegran & 4 & 4 & 4 & 4 & 4 & 4 & 4 & 4 & 4 \\
Cab-O-Sil & Glidan & 1 & 1 & 1 & 1 & 1 & 1 & 1 & 1 & 1 \\
TOTAL & & 100 & 100 & 100 & 100 & 100 & 100 & 100 & 100 & 100 \\
\hline
\end{tabular}


dilakukan pengayakan menggunakan mesh 100.

\subsection{Pembuatan granul}

Masing-masing serbuk simplisia dan bahan tambahan lainnya ditimbang sesuai dengan jumlah yang ditentukan. Selanjutnya, dicampur menggunakan tumbling mixer sampai homogen. Campuran tersebut kemudian dimasukkan ke dalam mesin slugging. Slug yang terbentuk direduksi ukurannya dengan mortir dan stamper, lalu diayak dengan mesh 16.

\subsection{Evaluasi mutu fisik granul}

\subsubsection{Uji distribusi ukuran partikel}

Pengujian ini menggunakan alat Retsch Vibrator dengan kecepatan getaran 60 rpm selama 20 menit dengan susunan pengayak sesuai dengan standar. Bobot granul dapat ditentukan melalui selisih bobot total dengan bobot pengayak. Selanjutnya, dibuat kurva distribusi ukuran granul [13].

\subsubsection{Uji bobot jenis mampat}

Gelas ukur $100 \mathrm{ml}$ yang telah berisi granul dicatat volumenya. Selanjutnya, tapping machine dijalankan pada tiap interval 100 ketukan hingga 500 ketukan. Volume diamati pada tiap 100 ketukan hingga perbedaan volume berikutnya kurang dari $2 \%$. Bobot jenis mampat dapat ditentukan dengan menggunakan rumus berikut [14], dimana $\rho_{\text {mampat }}=$ bobot jenis mampat, $\mathrm{m}=$ berat sampel granul, dan Vf = volume mampat serbuk granul.

$$
\rho_{\text {mampat }}=\frac{m}{V_{f}}
$$

\subsubsection{Uji bobot jenis nyata}

Granul ditimbang sebanyak 40 gram, kemudian dimasukkan mengalir sedikit demi sedikit ke dalam gelas ukur $100 \mathrm{ml}$ dengan kemiringan $45^{\circ}$. Selanjutnya, gelas ukur ditegakkan dengan cepat dan diamati volumenya. Bobot jenis nyata dapat dihitung menggunakan rumus berikut [14], dimana $\rho_{\text {nyata }}=$ bobot jenis nyata, $\mathrm{m}=$ berat sampel granul, dan Vo = volume granul.

$$
\rho_{\text {nyata }}=\frac{m}{V_{o}}
$$

\subsubsection{Uji rasio Hausner}

Rasio Hausner ditentukan melalui perbandingan bobot jenis mampat dengan bobot jenis nyata. Bila rasio Hausner $<1,25$ menunjukkan bahwa daya alir dari granul tersebut baik, sedangkan rasio Hausner 1,25-1,6 menunjukkan bahwa daya alir granul cukup, dan apabila $>1,6$ menunjukkan bahwa daya alir granul buruk [14].

$$
\text { Rasio Hausner }=\frac{\rho_{\text {mampat }}}{\rho_{\text {nyata }}}
$$

\subsubsection{Uji kandungan lembab}

Ditimbang granul sebanyak 5 gram, kemudian dianalisa kandungan lembabnya dengan menggunakan moisture content tester. Pada setiap 5 menit proses pengeringan akan menunjukkan bobot bahan dan proses pengeringan akan sempurna setelah interval 3 x 5 menit yang ditandai dengan bobot granul yang konstan. Persen kandungan lembab ditentukan dengan menggunakan rumus berikut, dimana $\mathrm{MC}=$ kandungan lembab, $\mathrm{W}=$ bobot granul awal, Wo = bobot granul akhir [15].

$$
M C(\%)=\left[\frac{(W-W o)}{W o}\right] \times 100 \%
$$

\subsubsection{Uji waktu rekonstitusi}

Ditimbang 5 g granul kemudian direkonstitusi dalam $100 \mathrm{ml}$ air dan diamati lama waktu sampai granul larut dalam air. Waktu rekonstitusi yang baik adalah kurang dari 300 detik [16].

\subsubsection{Uji pH larutan}

Pengukuran $\mathrm{pH}$ dilakukan dengan melarutkan $10 \%$ granul dalam $50 \mathrm{ml}$ air. Selanjutnya, $\mathrm{pH}$ diukur pada suhu ruang dengan menggunakan digital $p H$-meter yang telah dikalibrasi [17].

\subsection{Analisis data}

Data mutu fisik distribusi ukuran partikel dan rasio Hausner yang diperoleh dianalisis secara deskriptif, sedangkan data mutu fisik, seperti moisture content, waktu rekonstitusi, dan $\mathrm{pH}$ 
Tabel 2. Hasil evaluasi mutu fisik granul

\begin{tabular}{llllllll}
\hline Formula & & Hasil uji & & & & \\
\cline { 3 - 8 } & & $\begin{array}{l}\text { BJ mampat } \\
\text { (g/ml) }\end{array}$ & $\begin{array}{l}\text { BJ nyata } \\
\text { (g/ml) }\end{array}$ & $\begin{array}{l}\text { Rasio } \\
\text { Hausner }\end{array}$ & MC (\%) & pH & $\begin{array}{l}\text { Waktu rekons- } \\
\text { titusi (detik) }\end{array}$ \\
\hline Kumis Kucing & 1A & $0,77 \pm 0,00$ & $0,59 \pm 0,01$ & 1,31 & $6,06 \pm 0,14$ & $6,90 \pm 0,02$ & $41,20 \pm 3,43$ \\
& 1B & $0,81 \pm 0,01$ & $0,62 \pm 0,01$ & 1,30 & $3,26 \pm 0,21$ & $6,93 \pm 0,02$ & $42,06 \pm 3,18$ \\
& 1C & $0,78 \pm 0,00$ & $0,59 \pm 0,01$ & 1,32 & $4,51 \pm 0,14$ & $6,97 \pm 0,02$ & $34,90 \pm 1,48$ \\
\multirow{2}{*}{ Temulawak } & 2A & $0,76 \pm 0,02$ & $0,63 \pm 0,02$ & 1,21 & $6,47 \pm 0,67$ & $6,68 \pm 0,02$ & $233,96 \pm 10,31$ \\
& 2B & $0,87 \pm 0,00$ & $0,70 \pm 0,02$ & 1,24 & $3,62 \pm 0,07$ & $6,70 \pm 0,05$ & $291,97 \pm 6,84$ \\
& 2C & $0,85 \pm 0,02$ & $0,66 \pm 0,01$ & 1,28 & $5,14 \pm 0,46$ & $6,68 \pm 0,03$ & $264,61 \pm 8,09$ \\
Pegagan & 3A & $0,74 \pm 0,00$ & $0,58 \pm 0,00$ & 1,27 & $5,15 \pm 0,17$ & $6,07 \pm 0,02$ & $39,50 \pm 1,12$ \\
& 3B & $0,82 \pm 0,00$ & $0,62 \pm 0,01$ & 1,31 & $2,37 \pm 0,15$ & $6,17 \pm 0,03$ & $23,83 \pm 1,52$ \\
& 3C & $0,80 \pm 0,00$ & $0,61 \pm 0,01$ & 1,31 & $4,16 \pm 0,27$ & $6,10 \pm 0,01$ & $36,58 \pm 1,43$ \\
\hline
\end{tabular}

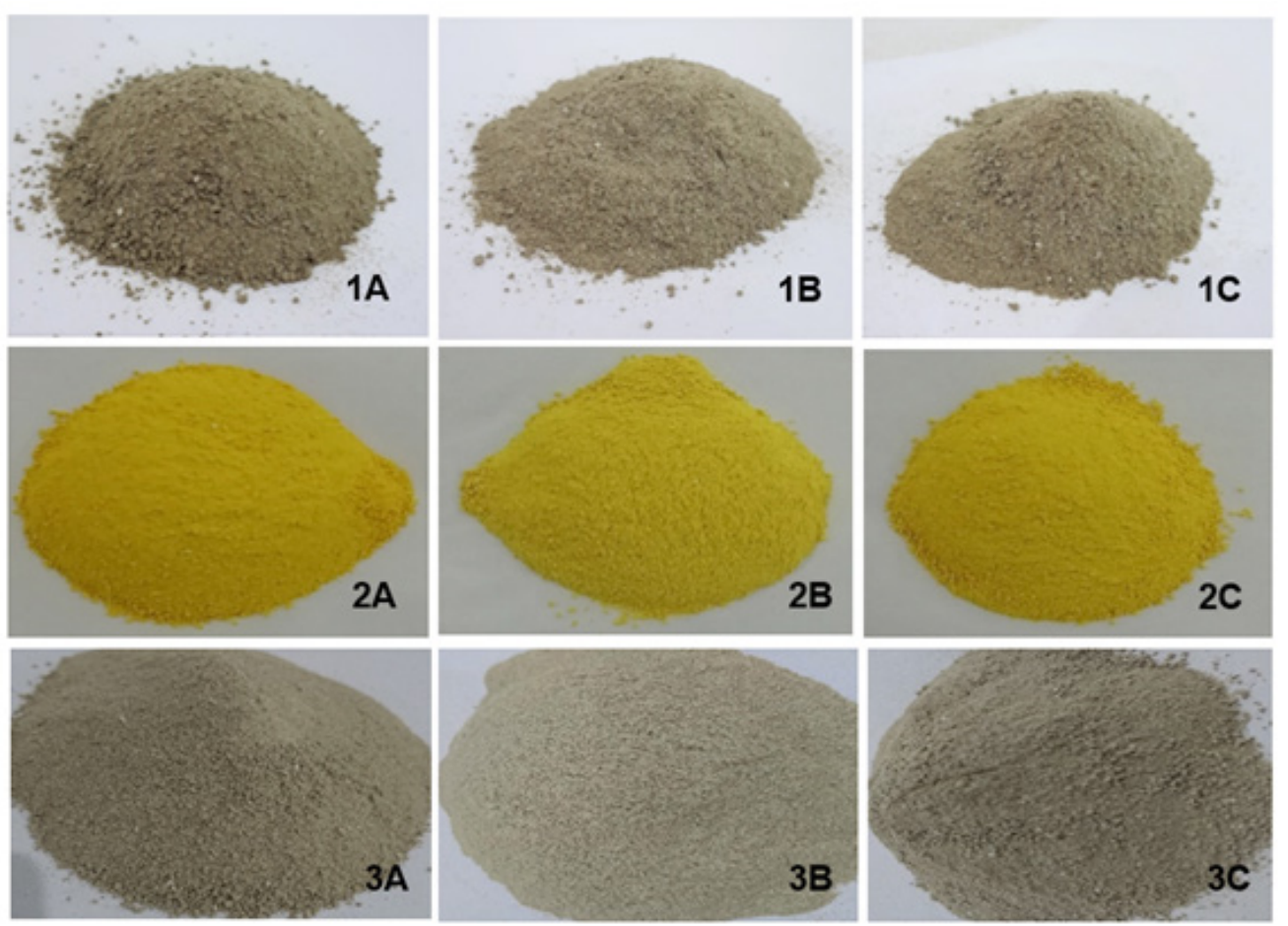

Gambar 1. Organoleptis granul Daun kumis kucing (1), Rimpang temulawak (2), dan Herba pegagan (3)

masing-masing formula dianalisis secara statistik menggunakan metode analisis varian (oneway ANOVA) menggunakan program PASW Statistic 18. Rancangan ini digunakan untuk mengetahui apakah terdapat perbedaan yang bermakna antar kelompok sampel dengan melihat harga significance (sig.).

\section{Hasil dan pembahasan}

\subsection{Organoleptis granul}

Formulasi granul diawali dengan mengayak masing-masing bahan dengan ayakan mesh 100, kemudian dilakukan pencampuran sampai homogen selama \pm 15 menit. Selanjutnya, dimasukkan ke dalam mesin slugging untuk dihasilkan slug. Hasil slug yang didapat kemudian direduksi ukuran partikelnya dengan menggunakan mesh 16. Hasil akhir didapatkan bentukan granul yang dapat dilihat pada Gambar 1. 
A

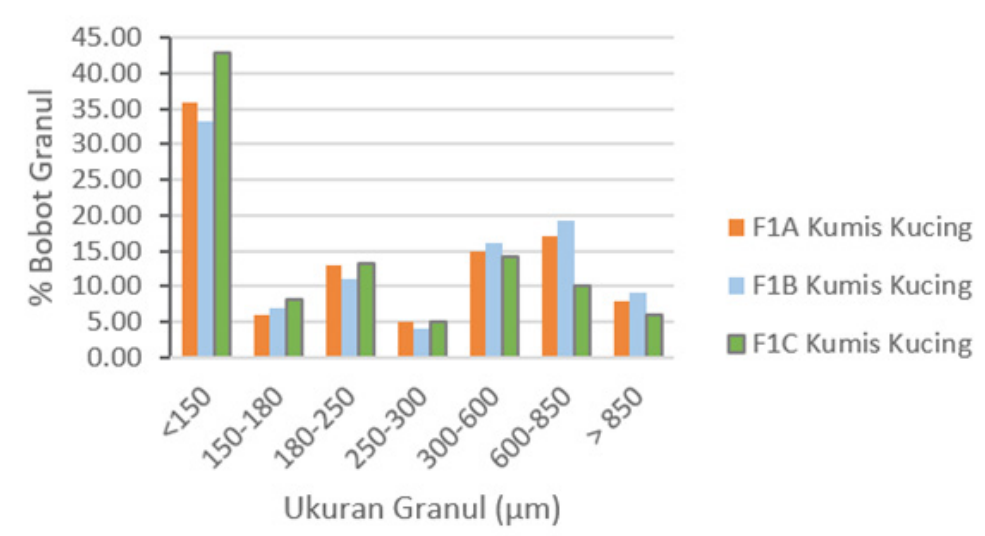

B

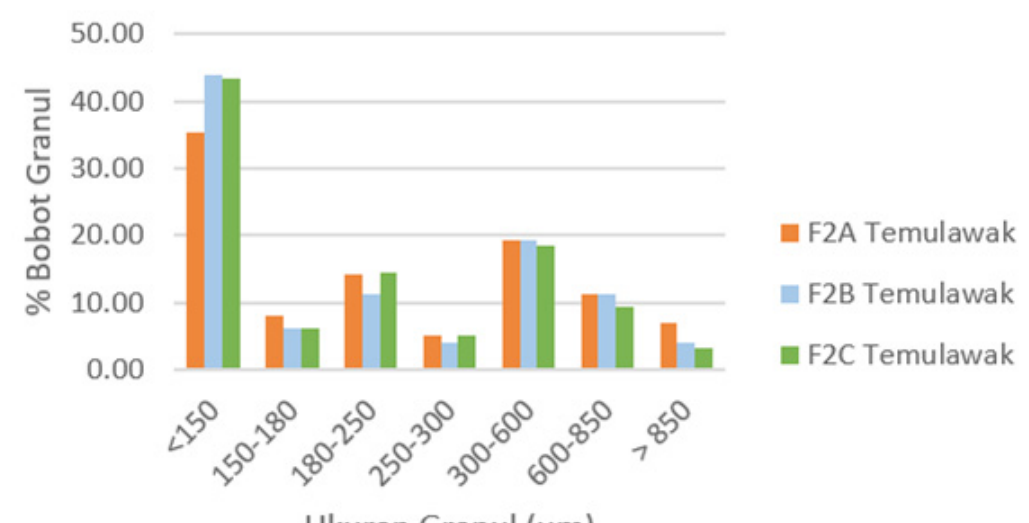

Ukuran Granul $(\mu \mathrm{m})$

C

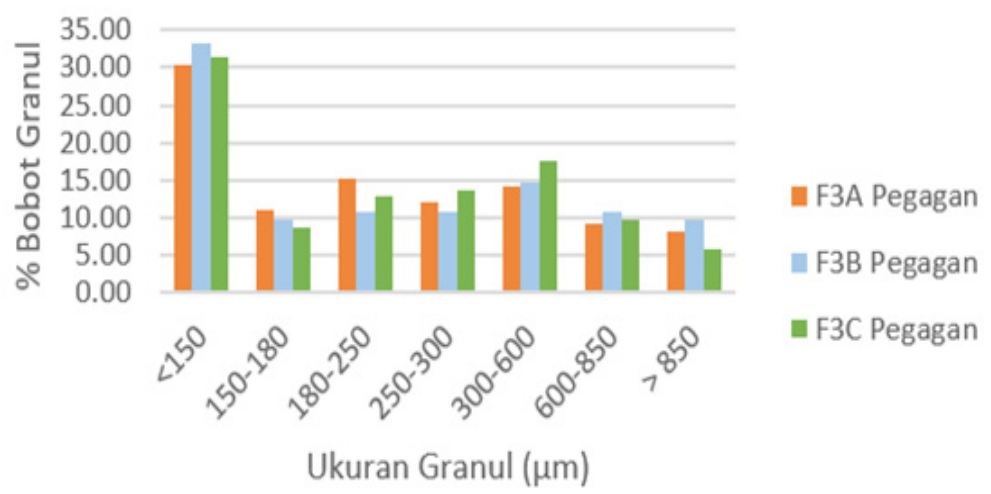

Gambar 2. Kurva distribusi ukuran partikel granul Daun kumis kucing (A), Rimpang temulawak (B), dan Herba pegagan (C)

\subsection{Hasil uji distribusi ukuran partikel}

Gambar 2 menunjukkan bahwa \% fraksi mayor ukuran partikel pada masing-masing formula berada pada rentang diameter $<150 \mu \mathrm{m}$. Variasi jenis dan jumlah pengisi tidak memberikan pengaruh yang signifikan terhadap distribusi ukuran partikel yang dihasilkan, seperti yang ditun- jukkan pada Gambar 2. Ukuran granul yang dihasilkan pada proses granulasi tersebut perlu untuk ditingkatkan dan diseragamkan. Agar tercapai tujuan tersebut maka pengikat PVP-K30 pada formulasi granul dengan metode granulasi kering perlu untuk ditingkatkan jumlahnya atau dikombinasi dengan pengikat lain untuk mendapatkan 
ukuran partikel yang lebih baik [18].

\subsection{Hasil uji bobot jenis mampat}

Hasil pengamatan bobot jenis mampat (Tabel 2) menunjukkan bahwa formula $1 \mathrm{~B}, 2 \mathrm{~B}$, dan $3 \mathrm{~B}$ dengan pengisi spray dried lactose memberikan nilai bobot jenis mampat yang lebih tinggi. Distribusi ukuran partikel spray dried lactose yang lebih besar, seragam, dan dengan morfologi yang lebih sferis memudahkan partikel untuk bergerak dan mengisi ruang pada wadah [12].

\subsection{Hasil uji bobot jenis nyata}

Hasil pengujian bobot jenis nyata (Tabel 2) memperlihatkan bahwa spray dried lactose pada formula 1B, 2B, dan 3B memberikan nilai yang lebih besar dibandingkan formula yang lain, berturut-turut sebesar 0,62; 0,70; dan 0,62.

\subsection{Hasil uji rasio Hausner}

Berdasarkan Tabel 2 terlihat bahwa sifat alir produk ruahan pada semua formula masuk dalam kategori fair-passable [19]. Hal ini menunjukkan bahwa granul kumis kucing, temulawak, dan pegagan masih dalam kategori cukup sampai bisa mengalir karena rasio Hausner berada pada rentang 1,21-1,31 [20, 14]. Apabila dikaitkan dengan hasil pengujian distribusi ukuran partikel menunjukkan bahwa ukuran yang tidak ideal dapat menggambarkan kurang baiknya karakteristik fisik dari granul tersebut, termasuk sifat alir. Sifat alir tersebut dapat ditingkatkan dengan membentuk granul yang lebih baik dan sferis sehingga akan membantu alirannya untuk mengisi ruang kempa. Selain itu, ukuran partikel yang relatif halus dan tidak seragam dapat menghambat laju alir dari granul dengan masuk ke dalam rongga-rongga antar partikel [10].

\subsection{Hasil uji kandungan lembab}

Hasil uji kandungan lembab ditunjukkan pada Tabel 2. Formula $1 \mathrm{~A}, 2 \mathrm{~A}$, dan $3 \mathrm{~A}$ memiliki kandungan lembab tertinggi dengan nilai berturut-turut 6,06; 6,47; dan 5,15\%. Nilai yang cukup tinggi pada formula A menunjukkan kesesuaian bahwa maltodekstrin sebagai pengisi pada formula tersebut bersifat sedikit higroskopis pada kelembaban relatif kurang dari 50\% [12]. Berdasarkan hasil uji anova, kandungan lembab antara ketiga formula menunjukkan perbedaan yang tidak signifikan $(\alpha>0,05)$.

\subsection{Hasil uji waktu rekonstitusi}

Hasil uji waktu rekonstitusi dapat dilihat pada Tabel 2. Berdasarkan hasil tersebut terlihat bahwa jenis pengisi memberikan pengaruh yang bermakna pada waktu rekonstitusi sediaan yang dihasilkan $(\alpha<0,05)$. Selain itu, waktu rekonstitusi juga dipengaruhi oleh karakteristik jenis simplisia yang digunakan seperti simplisiasimplisia yang memiliki sifat sukar larut dalam air [21]. Terbukti bahwa pada ketiga formula masing-masing simplisia menghasilkan waktu rekonstitusi yang berbeda bermakna $(\alpha<0,05)$. Pada formula 1 dan 3 menunjukkan waktu rekonstitusi berturut-turut, yaitu 34,90-41,20 detik dan 23,83-39,50 detik, sedangkan pada formula 2 menunjukkan waktu rekonstitusi 233,96-291,97 detik. Hal ini menunjukkan bahwa pada formula 1 dan 3 memiliki waktu rekonstitusi yang ideal yaitu kurang dari 300 detik [16]. Pada formula 2 memberikan waktu rekonstitusi yang paling lama dikarenakan granul yang terbentuk sulit untuk terbasahi oleh pelarut yang digunakan pada saat direkonstitusi. Oleh karena itu, perlu ditambahkan suatu zat pengelmusi agar granul dapat terdispersi sempurna dalam pelarut dan tidak mudah mengendap pada dasar larutan [21].

\subsection{Hasil uji pH larutan}

Pengujian $\mathrm{pH}$ dilakukan untuk mengetahui $\mathrm{pH}$ masing-masing sediaan formula 1,2 , dan 3 setelah direkonstitusi. Hal ini perlu dilakukan karena pH mempengaruhi stabilitas dan kenyamanan penggunaan suatu bentuk sediaan [17]. Berdasarkan Tabel 2 terlihat bahwa jenis pengisi memberikan pengaruh yang bermakna pada kumis kucing dan pegagan $(\alpha<0,05)$, sedangkan jenis pengisi tidak memberikan pengaruh yang bermakna pada temulawak $(\alpha$ 
$>0,05)$. Namun, hasil uji pH pada 3 formula tersebut telah memenuhi persyaratan spesifikasi sediaan terkait $\mathrm{pH}$ yang aman untuk dikonsumsi peroral yaitu antara 6,6 hingga 8,5 [22]. Hasil uji pH pada 3 formula setelah direkonstitusi berada pada rentang $\mathrm{pH}$ 6,07-6,97.

\section{Kesimpulan}

Dari penelitian yang telah dilakukan dapat disimpulkan bahwa granul herbal kumis kucing, temulawak, dan pegagan dengan pengisi maltodextrine dan spray dried lactose menunjukkan bahwa granul yang dihasilkan telah memenuhi spesifikasi mutu fiisk granul yang baik. Granul herbal dengan pengisi maltodextrine memberikan sifat alir granul yang lebih optimal apabila dibandingkan dengan menggunakan pengisi spray dried lactose atau kombinasi keduanya.

\section{Ucapan Terimakasih}

Ucapan terimakasih disampaikan kepada Lembaga Penelitian dan Pengabdian Masyarakat (LPPM) Universitas Surabaya atas pendanaan penelitian ini dalam skema Riset Unggulan 20172018 dengan nomor kontrak penelitian 107/SPLit/LPPM-01/Int/FF/XI/2017.

\section{Daftar Pustaka}

1. Kemenkes RI. Riset kesehatan dasar (RISKESDAS 2010). Jakarta: Badan Penelitian dan Pengembangan Kesehatan Kementrian Kesehatan RI; 2010.

2. Aditama TY. Jamu dan kesehatan edisi 2. Tawangmangu: Lembaga Penerbit Badan Penelitian dan Pengembangan Kesehatan; 2015.

3. Moghadam $\mathrm{MH}$, Imenshahidi $\mathrm{M}$, Mohajeri SA. Antihypertensive effect of celery seed on rat blood pressure in chronic administration. Journal of Medicinal Food. 2013;16(6):558-63.
4. Tabassum N, Ahmad F. Role of natural herbs in the treatment of hypertension. Pharmacognosy Reviews. 2010;5(9):30-40.

5. Ameer OZ, Salman IM, Asmawi MZ, Ibraheem ZO, Yam MF. Orthosiphon stamineus: traditional uses, phytochemistry, pharmacology, and toxicology: a review. Journal of Medicinal Food. 2012;15(8):113.

6. Oon SF, Nallappan M, Tee TT, Shohaimi S, Kassim NK, Sa'ariwijaya MSF, Cheah JH. Xanthorrhizol: a review of its pharmacological activities and anticancer properties. Cancer Cell International. 2015;15(100):1-15.

7. Harwoko, Pramono S, Nugroho AE. Triterpenoidrich fraction of Centella asiatica leaves and in vivo antihypertensive activity. International Food Research Journal. 2014;21(1):149-54.

8. Soares LAL, Ortega GG, Petrovick PR, Schmidt PC. Dry granulation and compression of spraydried plant extracts. AAPS Pharmaceutical Science Technology. 2005;6(3):359-66.

9. Kumar V, Manjunath K, Narayana A. Dry granulation technique for converting triphala churna as granules, tablets and organoleptic evaluation. International Research Journal of Pharmacy. 2015;6(6):321-6.

10. Parikh DM. Handbook of pharmaceutical granulation technology 2nd edition, Synthon Pharmaceuticals Inc.; 2005.

11. Yusof YA, Salleh FSM, Chin NL, Talib RA. The drying and tabletting of pitaya powder. Journal of Food Process Engineering. 2010;35(5):763-71.

12. Rowe RC, Sheskey PJ, Quinn ME. Handbook of pharmaceutical excipients 6th edition. Pharmaceutical Press; 2009.

13. Yulia R, Pradana AT, Sie SS, Suri FA. Formulation and physical characteristics of detam II soybean (Glycine $\max$ (L.) Merr) tablet with various concentration of silicon dioxide and magnesium stearate. Asian Journal of Pharmaceutical and Clinical Research. 2018;11(1):283-8.

14. Gupta R, Sharma P, Garg A, Soni A, Sahu A, Rai S, Rai S, Shukla A. Formulation and evaluation of herbal effervescent granules incorporated with 
Calliandra Haematocephala leaves extract. Indo American Journal of Pharmaceutical Research. 2013;3(6):4366-71.

15. Bhimte NA, Tayade PT. Evaluation of microcrystalline cellulose prepared from sisal fibers as a tablet excipient: a technical note. AAPS Pharmaceutical Science Technologies. 2007;8(1):56-62.

16. Rustina I, Maesaroh I. Pengaruh konsentrasi asam sitrat-asam tartrat dengan pemanis stevia terhadap formulasi granul effervescent saintifikasi jamu osteoarthritis (OA). Jurnal Farmasi Muhammadiyah Kuningan. 2019;4(1):2733.

17. Rahmawati IF, Pribadi P, Hidayat IW. Formulasi dan evaluasi granul effervescent ekstrak daun binahong (Anredera cordifolia (Tenore) Steen.). Pharmaciana. 2016;6(2):139-48.

18. Sapkal NP, Kilor VA, Bonde MN, Daud AS. Application of a convenient and cost-effective granulation technology for the formulation of tablets using conventional excipients. Asian Journal of Pharmaceutics. 2014;8(3):183-9.

19. Pharmacopeia US. United States Pharmacopeia and National Formulary (USP 37-NF 32). Rockville, MD: US Pharmacopeia. 2014.

20. Etti CJ, Yusof YA, Chin NL, Mohd TS. Effects of formulation on flowability of selected herbal powders using compendial methods and powder flow analyser. International Food Research Journal. 2016;23(Suppl):S225-30.

21. Kailaku SI, Sumangat J, Hernani. Formulasi granul efervesen kaya antioksidan dari ekstrak daun gambir. Jurnal Penelitian Pascapanen Pertanian. 2012;9(1):27-34.

22. Herniawan, Wahyuni S, Isamu KT. Kajian pengembangan formulasi produk minuman serbuk dari rumput laut Sargassum sp: studi kepustakaan. Jurnal Sains dan Teknologi Pangan. 2019;4(3):2264-71. 


\section{Vol. 3 No. 1 (2020): JUNE}

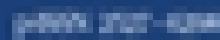

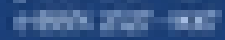

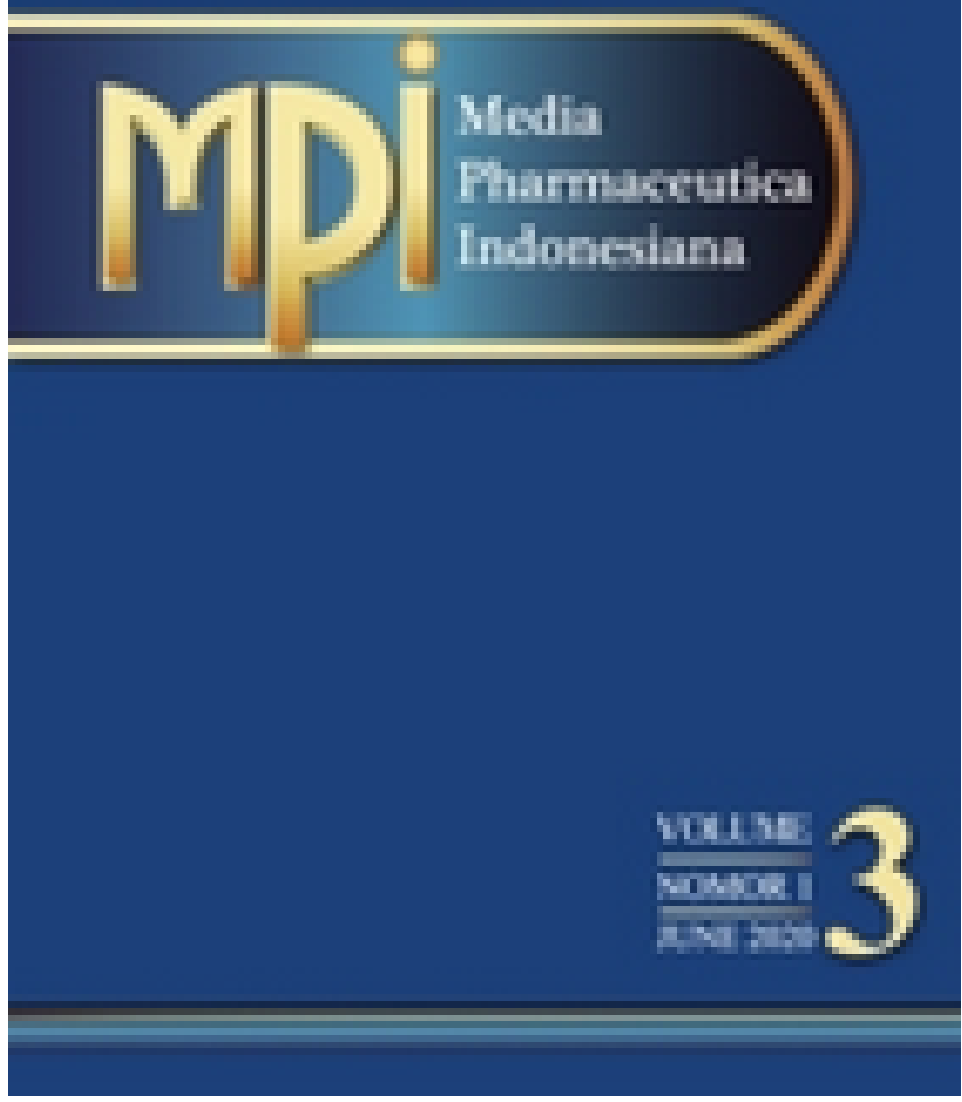


Journal Profile

\section{MPI (Media Pharmaceutica Indonesiana)}

eISSN : 25279017 I pISSN : 25276298

Health Science

Universitas Surabaya

\section{Cînta}

S4

Sinta Score

\section{v P Garuda}

Indexed by GARUDA

7

H-Index

7

H5-Index

Citations 


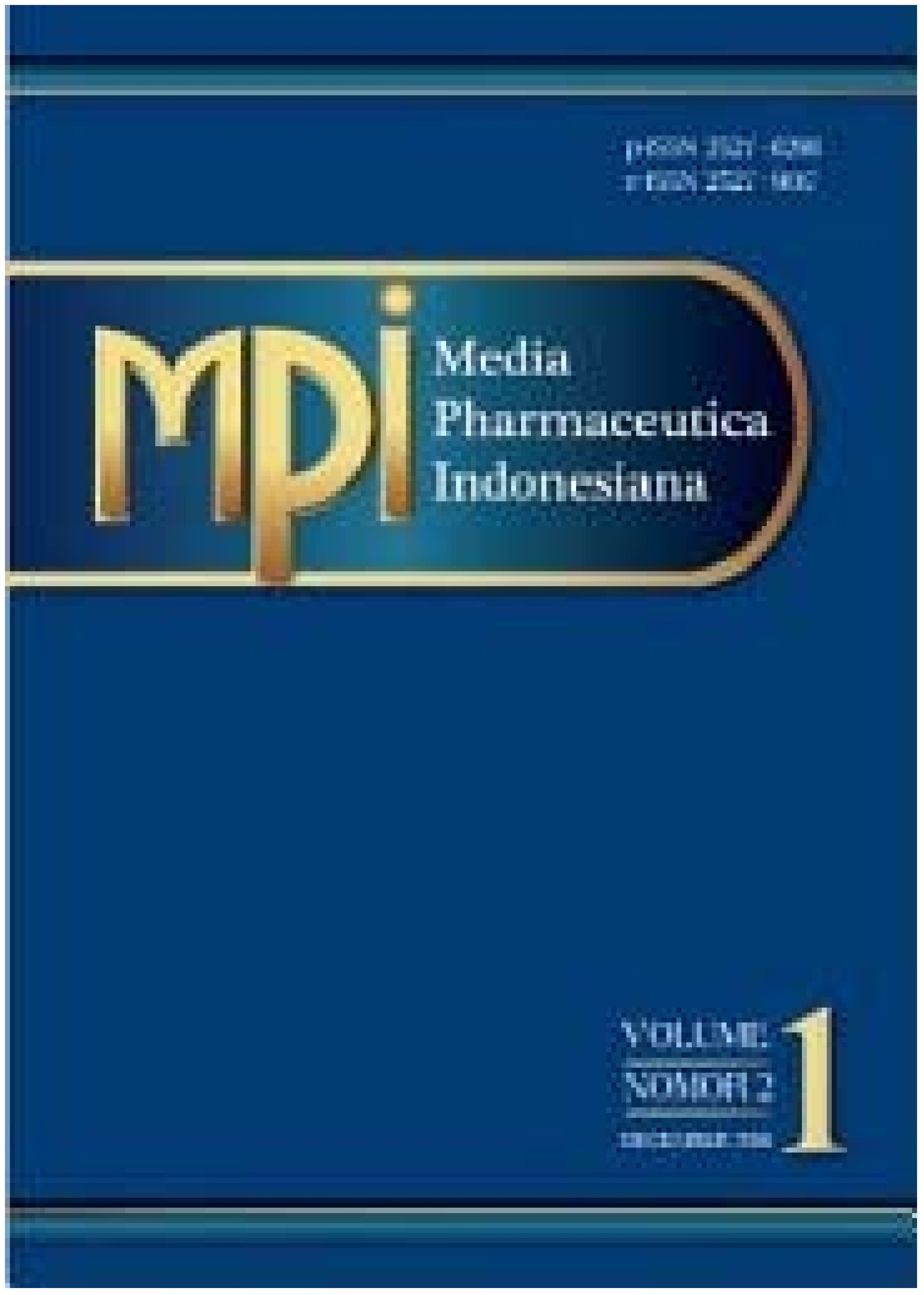


Fakultas Farmasi, Universitas Surabaya

Website I Editor URL 2019

Address:

Faculty of Pharmacy FF Building, 6th floor, University of Surabaya Jl. Raya Kalirungkut, Surabaya 60293, Indonesia Surabaya

@inta Accreditations

Email:

mpie,unit.ubaya.ac.id

Search..

Phone:

$$
\text { K } 《 \begin{array}{llllllll}
1 & 2 & 3 & 4 & 5 & \gg & \text { H }
\end{array}
$$

Patget pdofted:Total Records : 81

2021-08-13

Publications

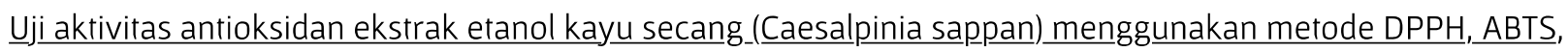
dan FRAP

F Setiawan, O Yunita, A Kurniawan

Media Pharmaceutica Indonesiana 2 (2), 82-89, 2018

Sirih merah (Piper crocatum Ruiz \& Pav.)kajian pustaka aspek botani, kandungan kimia, dan aktivitas

farmakologi

N Parfati, T Windono

Media Pharinaceutica Indonesiana 1 (2), 106-115, 2016

Pengembangan Model Hewan Coba Tikus Diabetes Mellitus Tipe 2 dengan Induksi Diet Tinggi Fruktosa Intragastrik

DD Wulansari, DD Wulandari

Media Pharmaceutica Indonesiana 2 (1), 41-47, 2018

Aplikasi zebrafish (Danio rerio) pada beberapa model penyakit eksperimental

A Yuniarto, EY Sukandar, I Fidrianny, IK Adnyana

MPI (Media Pharmaceutica Indonesiana) 1 (3), 116-126, 2017

Hubungan Persepsi Penyakit (Illness Perception) dengan Kontrol Gejala Asma pada Pasien Rawat Jalan

MPI (Media Pharmaceutica Indonesiana) 1 (2), 92-99, 2016 
Efek Pajanan Debu Kayu terhadap Gangguan Faal Paru

I Ma'rufi

MPI (Media Pharmaceutica Indonesiana) 1 (1), 45-52, 2016

Aktivitas Inhibisi Enzim Alfa-glukosidase dari Ekstrak Rimpang Bangle (Zingiber cassumunar Roxb.) secara In $\underline{\text { vitro }}$

A Yuniarto, N Selifiana

MPI (Media Pharmaceutica Indonesiana) 2 (1), 22-25, 2018

“Formulasi Sediaan Sabun Cuci Tangan Ekstrak Jeruk Nipis (Citrus aurantifolia) dan Efektivitasnya sebagai Antiseptik"

NIE Jayan, NB Kartini

Media Pharmaceutica Indonesiana 1 (4), 2017

Pengembangan Formula dan Uji Stabilitas Fisik-pH Sediaan Gel Facial Wash yang Mengandung Ekstrak Etanol

Kulit Kayu Kesambi

G Eugresya, C Avanti, SA Uly

Media Pharmaceutica Indonesiana 1 (4), 181-188, 2017

Efek protektif_pemberian ekstrak etanol herba meniran (Phyllanthus niruri L.) terhadap aktivitas dan kapasitas fagositosis makrofagg_peritoneum tikus

W Sriningsih, A Eru

Media Pharmaceutica Indonesiana 6 (2), 91-6, 2006

Page 1 of 9 | Total Records : 81

$$
\text { 14 《 } \begin{array}{llllllll}
1 & 2 & 3 & 4 & 5 & \# & \boldsymbol{H}
\end{array}
$$

Citation Statistics 


\section{Editorial Team}

\section{Editor in Chief}

Kartini, S.Si., M.Si., Apt., Ph.D. Sinta Scopus

\section{Associate Editor}

Dr. Herman J. Woerdenbag Scopus

Assoc. Prof. Dr. Omboon Vallisuta Scopus

Dr. Menino Osbert Cotta Scopus

Dr. Christina Avanti M.Si., Apt. Sinta Scopus

Prof. Dr. Dwi Setyawan, S.Si., M.Si., Apt. Sinta Scopus

Dr. Rika Yulia, S.Si., SpFRS., Apt. Sinta Scopus

Dr. Oeke Yunita, S.Si., M.Si., Apt. Sinta Scopus

Rr. Retno Widyowati, S.Si., M.Pharm., Apt. Sinta Scopus

Dr. Finna Setiawan, S.Farm., M.Si. Sinta Scopus

Desak Ketut Ernawati, S.Si., Apt., M.Pharm., Ph.D. Sinta Scopus

Dr. Susi Ari Kristina, M.Kes., Apt. Sinta Scopus

Dr. Dini Kesuma, S.Si., M.Si., Apt. Sinta Scopus

Hendri Wasito, S.Si., M.Sc., Apt Sinta Scopus

Prof. I Ketut Adnyana, M.Si., Ph.D. Sinta Scopus

\section{Administrator}

Siti Kusnul Khotimah

Maya Harfia A., A.Md. 


\section{Vol. 3 No. 1 (2020): JUNE}

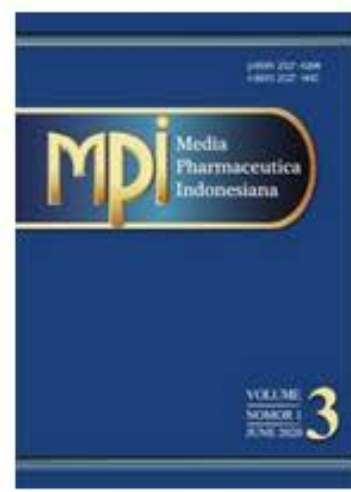

DOI: https://doi.org/10.24123/mpi.v3i1

Published: $2020-06-20$

\section{Original Research Articles}

Pengembangan Granul Herbal Pada Tanaman Kumis Kucing, Temulawak, dan Pegagan dengan Pengisi Maltodextrine dan Spray Dried Lactose

Roisah Nawatila, Diva Amadea Nabilla, Fransiska Levina Oktaviani, Rista Noer Efendi, Ade Ayu Kintan Anjarsari, Chintya Dewi Tanuwijaya, Rahma Anida Putri, Aditya Trias Pradana

All Abstract Views: 333 alc PDF Downloads: 415 \& DOI https://doi.org/10.24123/mpi.v3i1.2790

[D PDF

Karakterisasi Senyawa Metabolit pada Kultur Anggrek Dendrobium anosmum-gigantea

Alfian Hendra Krisnawan, Sajekti Palupi, Sitti Suhartina, Alrivani Eka Yuli Saputri, I Gusti Agung Made Shinta Ari Putri, Ni Made Swasti Wandhini, Oeke Yunita

1/ Abstract Views: 311 and PDF Downloads: 341 \& DOI https://doi.org/10.24123/mpi.v3i1.2417

[ $\mathrm{G}$ PDF

Rhizome Buds Disinfection for Preparation of Red Ginger (Zingiber officinale Roxb. var. rubrum Rosc.) In Vitro Culture

Popy Hartatie Hardjo, Alfian Hendra Krisnawan

All Abstract Views: 243 and PDF Downloads: 361 DOI https://doi.org/10.24123/mpi.v3i1.2836

圆 PDF 
Simultaneous HPLC Determination of Lidocaine Hydrochloride and Hexachlorophene in a Suppository Product Cece Furwanti, Kusuma Hendrajaya, Gunawan Indrayanto

11 Abstract Views: 215 년 PDF Downloads: 203 \& DOI https://doi.org/10.24123/mpi.v3i1.2455

[ PDF

Cost Saving of Stress Ulcer Prophylaxis Used in Non-Intensive Care Unit (ICU) Inpatients

Hening Pratiwi, Laksmi Maharani, Ika Mustikaningtias

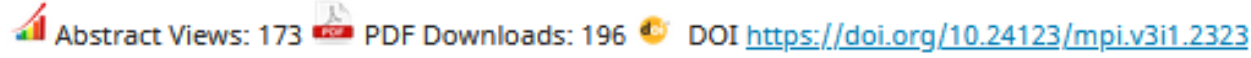

[

Profil Penggunaan Antibiotik Pada Pasien Pediatri Rujukan Berdasarkan Sistem Defined Daily Dose (DDD) Nurul Fatmawati Pua Upa, Widyati Widiaty, Frans O.H. Prasetyadi

11 Abstract Views: 251 PDF Downloads: 180 \&OI https://doi.org/10.24123/mpi.v3i1.2503

[ PDF

Efektivitas Profilaksis Primer Filgrastim Pada Pasien Kanker Payudara terhadap Insiden Neutropenia Andri Utomo, Widyati Widyati, Dwi Hari Susilo

all Abstract Views: 174 ä PDF Downloads: 121 Dor https://doi.org/10.24123/mpi.v3i1.2831 